\title{
XXVI Encontro da Associação Nacional dos Programas de Pós-Graduação em Administração: Características, Processo e Resultados
}

\author{
Rogério H. Quintella
}

\begin{abstract}
Resumo
Este texto tem o objetivo de divulgar as principais características do XXVI Encontro da Associação Nacional dos Programas de Pós-Graduação em Administração. Com este propósito, são apresentadas diversas informações sobre o universo de autores que submeteram trabalhos ao evento. Descreve-se detalhadamente o processo de seleção e, por fim, são discutidos os resultados deste processo em termos da distribuição de trabalhos aceitos por instituição, para aquelas que tiveram mais do que $5 \%$ dos trabalhos aceitos em cada área temática. O texto mostra ainda o crescimento proporcional das diferentes áreas temáticas. Observa-se a importância do número de autores ainda pós-graduandos e, principalmente, pós-graduandos de dedicação parcial, tanto no nível de mestrado quanto no de doutorado. Por fim, o trabalho fornece indicações quanto ao desempenho dos diferentes grupos de autores no processo seletivo do evento.
\end{abstract}

Palavras-chaves: Encontro da ANPAD; funcionamento; resultados; autores.

\begin{abstract}
This paper describes the main characteristics of the XXVI Conference of the Brazilian Academy of Management, Business and Administrative Sciences (ENANPAD). Considerable information is given about the authors who submitted papers to the event. A detailed description of the selective process is presented, as well as the results, in terms of performance of universities and institutions with more than $5 \%$ of accepted papers in each area. Furthermore, the proportional growth of each of the event's thematic areas are shown. The participation of authors who are still students and mainly, part-time-graduation-students is measured and finally, some indication is given about the performance of the different groups of authors in the selective process for the conference.
\end{abstract}

Key words: ANPAD Conference; process; results; authors. 


\section{INTRODUÇÃO}

Este texto tem como finalidade trazer ao conhecimento do público alguns dados e resultados referentes ao XXVI Encontro da Associação Nacional dos Programas de Pós-Graduação em Administração (ENANPAD), realizado em Salvador, BA, em setembro de 2002. Alguns destes dados referem-se a aspectos tradicionalmente monitorados em encontros anteriores; outros surgem pela primeira vez, devido a um novo conjunto de informações referentes aos autores, solicitadas a partir de 2002 na submissão de seus trabalhos. A maior parte destes resultados já foi apresentada ao público durante a abertura do evento. Foi justamente o interesse gerado na ocasião e o volume de cópias da apresentação requisitadas, que inspiraram a confecção deste texto.

Vários trabalhos foram publicados ao longo dos últimos anos analisando a produção científica dos encontros da ANPAD como, por exemplo, Machado-daSilva, Cunha e Amboni (1990), Vergara e Carvalho Jr. (1995), Bertero, Caldas e Wood Jr. (1998), Hoppen et al. (1998), Caldas, Tonelli e Lacombe (2002), Rodrigues Filhos (2002) e Teixeira Jr. (2002). Em nenhum destes trabalhos, porém, buscouse resposta a questões como volumes e taxas de submissão do evento, caracterização dos autores, demanda por área, processo seletivo, distribuição da produção selecionada, desempenho de programas e desempenho de grupos de autores. Estas são algumas das questões que este trabalho traz agora à discussão da comunidade.

\section{Volume e Taxa de Submissões}

O XXVI ENANPAD trouxe consigo elevação de mais de 40\% no número de trabalhos submetidos, em relação a 2001, atingindo o montante de 1.998 entradas no sistema. Nesse sentido, deve-se observar que a taxa média de crescimento de submissões entre 1997 e 2001 foi de aproximadamente 16\% ao ano. Cabe aqui, portanto, colocar uma questão ainda não respondida: o que motivou o aumento tão grande na submissão de trabalhos no ano passado? Eis, a seguir, algumas das possíveis explicações. A primeira é a crescente qualidade dos encontros. A segunda é a transparência dos critérios de avaliação da CAPES e a importância relativa dos encontros da ANPAD no seu sistema de pontuação de publicações. A terceira é o simples crescimento do número de programas de pós-graduação 
na área. A quarta, e última, é a atratividade da cidade de Salvador, onde se realizou o evento. Provavelmente nenhuma das razões isoladamente explica o fenômeno, mas uma combinação delas.

É importante salientar que as quase 2.000 submissões envolveram mais de 3.500 autorias; ou seja, uma média superior a 1,7 autores por submissão.

Outro aspecto interessante é a taxa diária de submissão de trabalhos. Conforme o que foi mostrado em 25 de setembro passado, a média de submissões dos primeiros 28 dias em que o sistema esteve aberto foi de 19 submissões por dia, elevando-se este índice para 130 no fim de semana que antecedeu o encerramento do prazo de submissões e, finalmente, um total de 1.100 trabalhos submetidos na segunda- feira, último dia do prazo.

Esses números parecem retratar não apenas práticas profundamente arraigadas, de caráter cultural, caricaturadas pela célebre expressão "brasileiro deixa tudo para a última hora”, mas talvez e, principalmente, a realidade extenuante de profissionais que se desdobram entre múltiplas tarefas típicas, como a preparação de aulas, orientações, pesquisa, produção científica etc.

Entre as conseqüências do fluxo exagerado ocorrido no último dia do prazo, estão os custos do hiperdimensionamento necessário ao sistema de informática, de forma a garantir o atendimento a esta enorme oferta de trabalhos de última hora.

\section{Outros Números do Evento}

Enquanto a submissão de trabalhos cresceu cerca de 43\% entre 2001 e 2002, observa-se que o número de submissões em duplicata sobe de 84 para 176, representando elevação de mais de $100 \%$. Já o número de trabalhos reprovados por não atenderem aspectos referentes à formatação contidos na chamada de trabalhos praticamente triplicou, passando de um total de 73 em 2001 para 230 no ano passado. Essa elevação é mais importante e significativa que a anterior (a das duplicatas) e deve ser atribuída a dois fatores. O primeiro, assim como no caso das duplicatas, parece estar associado ao maior número de estreantes no sistema. $\mathrm{O}$ segundo fator envolve maior rigor na exigência de que se cumpra o formato de trabalhos especificado na chamada. Este rigor reflete a filosofia adotada pela atual Diretoria Executiva da ANPAD para seus eventos, ou seja, crescimento quantitativo apenas enquanto associado ao crescimento qualitativo dos trabalhos. 
Um aspecto fundamental que deve aqui ser destacado é o fato de que cada trabalho submetido é avaliado por dois técnicos, no que tange ao atendimento às normas de formatação solicitadas, à existência de vírus e aos softwares inseridos nos textos. Os trabalhos com problemas de formato são ainda enviados ao Diretor Científico, sob o sistema de blind review, para uma decisão final, antes de serem descartados do sistema seletivo. Após todo esse custoso processo de pré-avaliação dos textos, resultaram 1.585 trabalhos a serem avaliados em seus aspectos científicos e de conteúdo, um crescimento de 28\%. Um total de 207 avaliadores trabalharam nesse processo em 2002, um crescimento de 37\%, classificando os trabalhos segundo os critérios discutidos na seção seguinte do presente texto. A maior elevação do número de avaliadores em comparação com o número de trabalhos avaliados revela também uma política que busca sacrificar menos os avaliadores (em 2002 estes leram, em média, 6\% a menos que em 2001) e, paralelamente, ampliar e renovar o elenco de profissionais que exercem tal papel.

Por fim, cabe comentar que o número de inscritos no evento subiu cerca de $20 \%$ em 2002, atingindo um total de aproximadamente 850 congressistas. Apesar do menor impacto percentual deste crescimento, deve-se observar que o encontro de 2002 foi realizado a alguns milhares de quilômetros dos centros geográficos de maior produção acadêmica no país. Assim se forem considerados os custos de transporte envolvidos, os $20 \%$ mencionados parecem ser um indicador de crescimento bastante positivo, principalmente ao lembrar que o encontro anterior foi realizado a apenas algumas dezenas de quilômetros de São Paulo.

\section{Processo de Análise Científica dos Trabalhos}

Em linhas gerais, a avaliação de cada um dos 1.585 trabalhos analisados passou pelas etapas listadas abaixo.

- Análise preliminar pelo coordenador de área temática: nesta etapa procura-se identificar, entre os avaliadores indicados para cada área, quais têm mais familiaridade com os conteúdos de cada trabalho.

. Encaminhamento a avaliadores: nesta etapa o sistema de informática bloqueia, automaticamente, o envio de trabalhos para avaliadores do mesmo Estado das instituições de ensino e pesquisa em que atuam os autores de cada texto. São admitidas exceções em casos particulares. Para tanto, o coordenador deve justificar a exceção à Direção Científica, a qual, aceitando a justificativa, solicita à secretaria da ANPAD a liberação manual de protocolos que permitem ao sistema informatizado o envio de cada trabalho individualmente. 
. Análise preliminar: aqui cada um dos avaliadores analisa se o trabalho tem méritos suficientes para entrar na análise detalhada ou não. Em caso positivo, o trabalho passa por detalhado sistema de análise, descrito a seguir.

. Avaliação segundo os dez quesitos preestabelecidos: (1) clareza, pertinência e consecução dos objetivos; (2) qualidade da redação e organização do texto; (3) originalidade do trabalho; (4) qualidade da revisão de literatura; (5) relevância do tema; (6) consistência teórica do trabalho; (7) metodologia utilizada; (8) análise de dados e resultados; (9) conclusões; e (10) contribuição do trabalho para o conhecimento na área temática. Cada um desses quesitos recebe nota de $0 \mathrm{a}$ 10 da parte de cada um dos dois ou três avaliadores que o leram.

. Intermediação do coordenador: a intermediação do coordenador ocorre quando as avaliações realizadas são discrepantes. Nesse caso a avaliação do coordenador se soma às demais, sem que haja qualquer diferença entre o peso da sua avaliação e aquela dos seus avaliadores.

. Montagem de planilha de resultados: os resultados de todo o processo de avaliação são tabulados para fins de análise estatística.

- Aplicação do escore z: cada uma das notas médias dada por cada avaliador a cada trabalho é transformada em número de desvios-padrões em relação à sua média de notas (do avaliador). Dessa forma, procura-se minimizar o eventual viés (maior ou menor rigor) dos avaliadores. Observa-se que esse é um procedimento padrão em concursos públicos, vestibulares etc.

. Ranqueamento por escore em cada área: de forma simplificada, pode-se dizer que nessa etapa a média dos escores $\mathbf{z}$ de cada trabalho é listada, criando-se um ranking de trabalhos para cada área temática.

. Avaliação de ponto de corte pelo coordenador de área temática: esse último passo consiste na observação e na palavra final de cada coordenador, de posse do ranking acima mencionado, quanto ao número máximo de trabalhos que pode ser aceito, dentro do que ele considera ser o padrão mínimo de qualidade a ser mantido em sua área. Esse número é balizado pelos números máximo e mínimo de trabalhos de cada área, estipulados pela Direção Executiva da ANPAD a partir de questões como número de salas disponíveis, duração e número de sessões a serem apresentadas ao longo do evento.

Em 2002, após todo este processo foram selecionados 556 trabalhos, contra 428 em 2001, representando crescimento de 30\%. 


\section{Distribuição de Submissões por Área Temática}

A Figura 1, a seguir, mostra a distribuição de trabalhos por área temática como percentual do total de trabalhos submetidos. O primeiro grupo é o das áreas com percentuais entre 8,5\% e 10,1\% do total de submissões. Há seis áreas temáticas neste grupo, sendo as duas maiores Comportamento Organizacional e Estratégia nas Organizações. É interessante observar que, ao menos em uma grande conferência internacional, a da Academy of Management, de 2002, foram exatamente essas as duas áreas com maior percentual de submissão. Ainda neste grupo das maiores áreas encontram-se Administração da Informação; Marketing; Gestão de Pessoas e Relações de Trabalho; e Contabilidade e Controladoria Gerencial.

\section{Figura 1: Distribuição (\%) das Submissões por Área Temática}

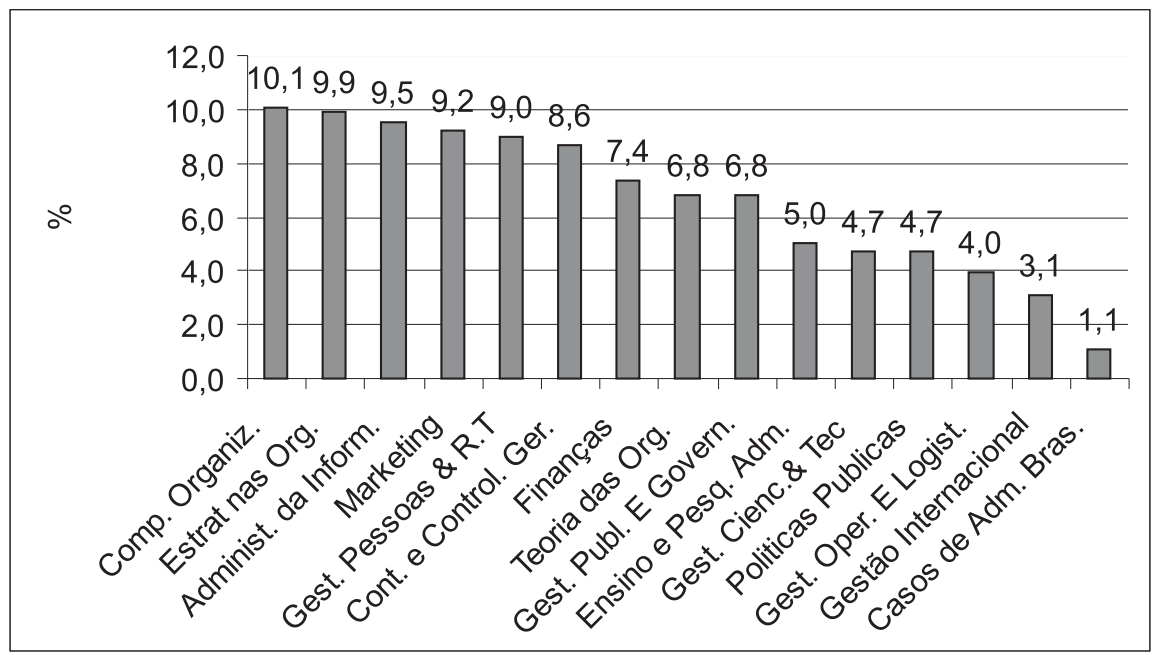

Fonte: banco de dados da ANPAD.

Ainda na Figura 1 pode-se observar o segundo grupo, composto por três áreas de médio porte, em termos de oferta de trabalhos ao encontro: Finanças; Teoria das Organizações; e Gestão Pública e Governança. O terceiro grupo de áreas teve o percentual de submissões variando entre 3,1\% e 5\%, englobando as seguintes áreas: Ensino e Pesquisa em Administração; Gestão de Ciência e Tecnologia; Políticas Públicas; Gestão de Operações e Logística; e Gestão Internacional. Por fim, observa-se que pouco mais de 1\% das submissões foram feitas para a área de Casos de Administração Brasileira. Deve-se salientar, porém, que nessa última área exigiu-se a participação conjunta de acadêmicos e executivos e o formato de painel, o que, certamente, limitou bastante a submissão de 
trabalhos. Outro aspecto importante no que tange às áreas temáticas é o fato de que várias destas áreas foram criadas ou redefinidas há apenas dois anos, tais como Comportamento Organizacional, Políticas Públicas, Ensino e Pesquisa em Administração, Gestão Internacional e Casos de Administração Brasileira. A Figura 2, a seguir, mostra o crescimento percentual da submissão por áreas. Como pode ser visto na figura, as novas áreas tiveram crescimento significativo, justificando não apenas a criação, mas também a manutenção destas áreas temáticas nos próximos encontros.

Figura 2: Crescimento Percentual por Área Temática entre os Encontros da ANPAD de 2001 e 2002

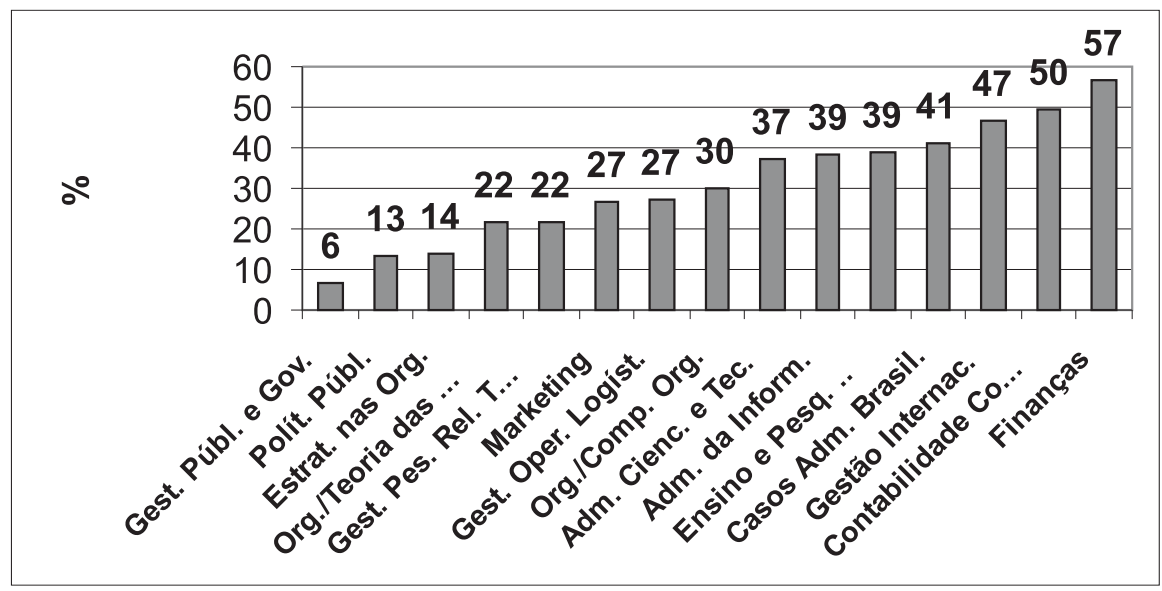

Fonte: banco de dados da ANPAD.

Deve-se destacar também na Figura 2 o enorme crescimento das áreas de Contabilidade e Controladoria Gerencial e Finanças.

Na seção que se segue, apresentam-se dados sobre uma parcela importante da comunidade de pesquisadores atuando na área de Administração e nas suas interfaces: o universo de autores que submetem trabalhos aos nossos encontros.

\section{Quem Submete Trabalhos aos Encontros da ANPAD?}

A pergunta que serve de título a esta seção só começa a ser respondida em 2002. A Figura 3 mostra que aproximadamente 52\% dos autores de trabalhos submetidos ao XXVI ENANPAD são professores plenos. O adjetivo é usado 
aqui para diferenciar esse grupo daquele em que os autores, no plano individual, são simultaneamente professores e estudantes.

\section{Figura 3: Classificação dos Autores e Co-Autores de Trabalhos Submetidos ao XXVI ENANPAD em Função da sua Ocupação}

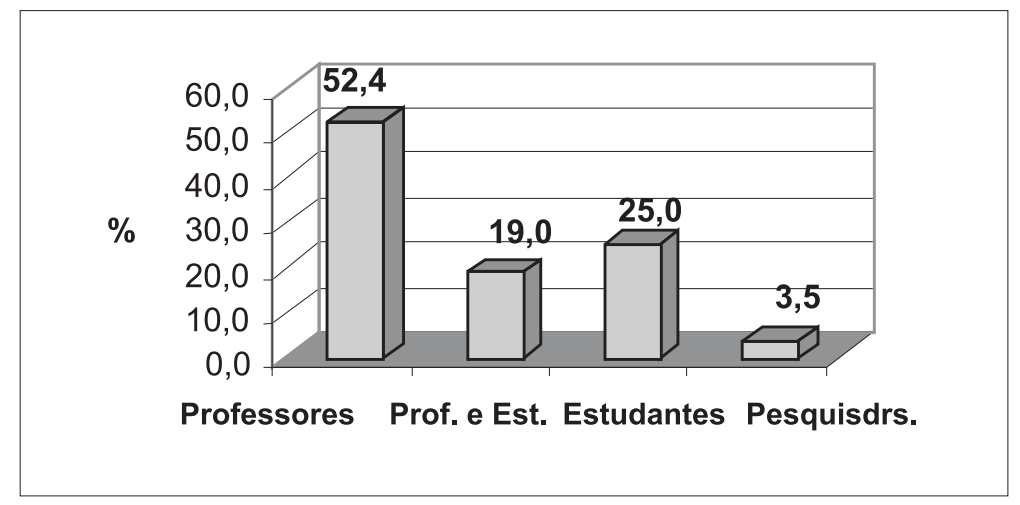

Fonte: banco de dados da ANPAD.

Como pode ser observado na Figura 3, 25\% dos autores são estudantes, seja de mestrado, doutorado e marginalmente graduação, 3,5\% se definem apenas como pesquisadores e 19\%, apesar de ainda serem estudantes, já lecionam em cursos de nível superior. Cada um desses grupos é melhor caracterizado a seguir.

\section{Quem São os Professores que Submetem Trabalhos aos Encontros da ANPAD?}

A Figura 4 apresenta a classificação daqueles que são professores, quer também estudantes, quer não. O que se observa é que a maior parte desses professores leciona simultaneamente nos níveis da pós-graduação e da graduação (mais de $62 \%$ ). Apenas cerca de $21 \%$ pode dedicar-se exclusivamente ao ensino de pós-graduação.

A Figura 4 mostra também que 16\% dos professores ensinam apenas na graduação. Quase a totalidade desses 16\% é também estudante de pós-graduação, sendo este, provavelmente, o seu principal vínculo com a ANPAD.

Ainda visando a uma caracterização preliminar de quem são os professores que submetem trabalhos aos encontros da ANPAD, observa-se que 21,3\% deles identificam-se como professores apenas de pós-graduação, mais da metade (58\%) leciona apenas em cursos lato sensu, um quarto deles leciona em ambos os níveis, e $17 \%$ leciona apenas no stricto sensu. 
Figura 4: Distribuição da Submissão de Trabalhos entre Subgrupos de Professores

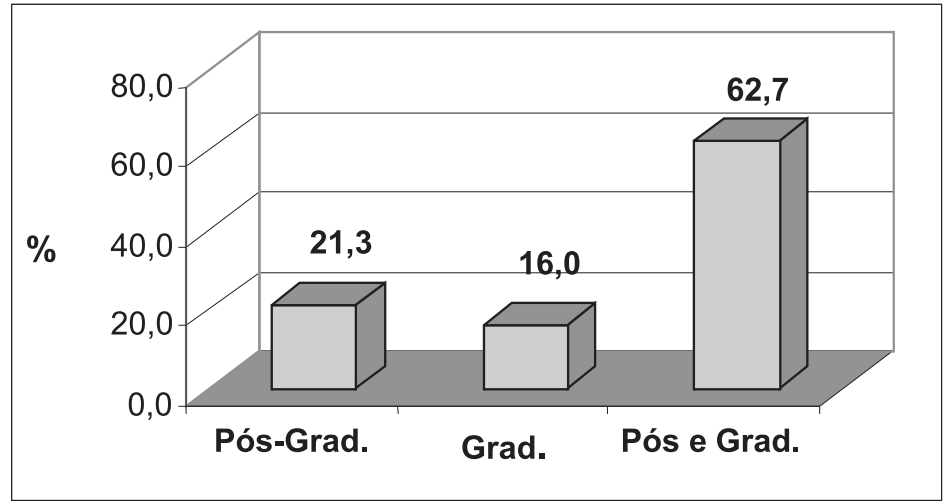

Fonte: banco de dados da ANPAD.

\section{Quem São os Estudantes que Submetem Trabalhos aos Encontros da ANPAD?}

Outra questão interessante e que começa a ser respondida, é sobre quem são os estudantes que submetem trabalhos aos nossos encontros. A Figura 5 mostra que, em sua maioria (54\%), são estudantes de mestrado, enquanto aproximadamente $37 \%$ deles são estudantes de doutorado.

Figura 5: Distribuição da Submissão de Trabalhos por Subgrupos de Estudantes

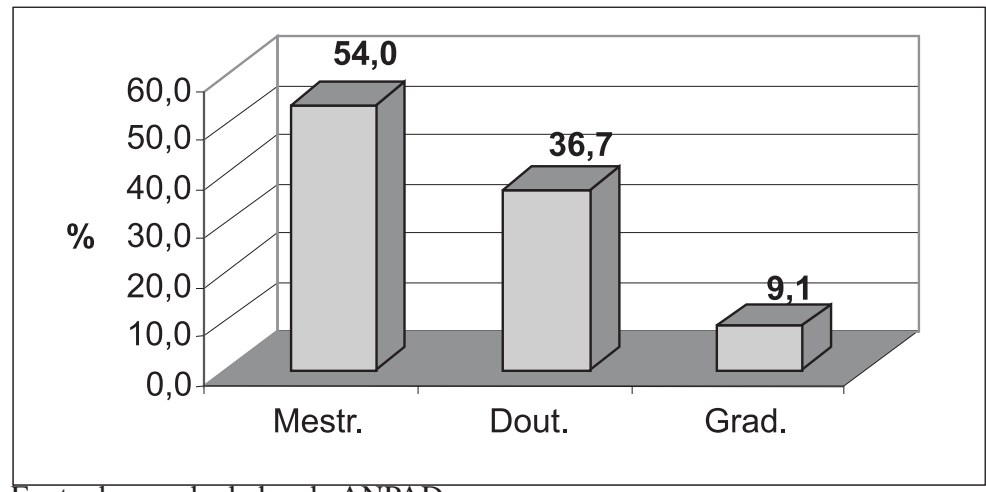

Fonte: banco de dados da ANPAD. 
Deve-se observar aqui que esses percentuais representam, em termos absolutos, mais de 800 submissões de mestrandos e 500 submissões de doutorandos. Esses números dão uma boa idéia da importância e da penetração do encontro na pós-graduação brasileira na área.

Por fim, salienta-se que 9,1\% dos estudantes que submeteram trabalhos são alunos de graduação, provavelmente, em sua grande maioria, bolsistas de iniciação científica.

\section{Quem São os 'Estudantes-Professores' que Submetem Trabalhos aos Encontros da ANPAD?}

A Figura 6, a seguir, mostra que mais de $62 \%$ dos estudantes-professores são, mais especificamente, doutorandos-professores, ou seja, fazem cursos de doutorado, mas não em regime de dedicação exclusiva, como pressupõe e exige a quase totalidade dos programas de doutorado no país. Por outro lado, aproximadamente $37 \%$ deles são mestrandos-professores, ou seja, estudantes que ainda sequer completaram seus mestrados, porém já lecionam. Por fim, há uma terceira categoria que, ao invés de graduandos-professores, provavelmente seriam mais bem apelidada de professores-graduandos. Trata-se, aparentemente, de um pequeno grupo de professores que se encontram matriculados em uma segunda graduação.

Figura 6: Distribuição dos Autores que se Identificam Simultaneamente como Estudantes e Professores em Função do Nível do Curso em que São Estudantes

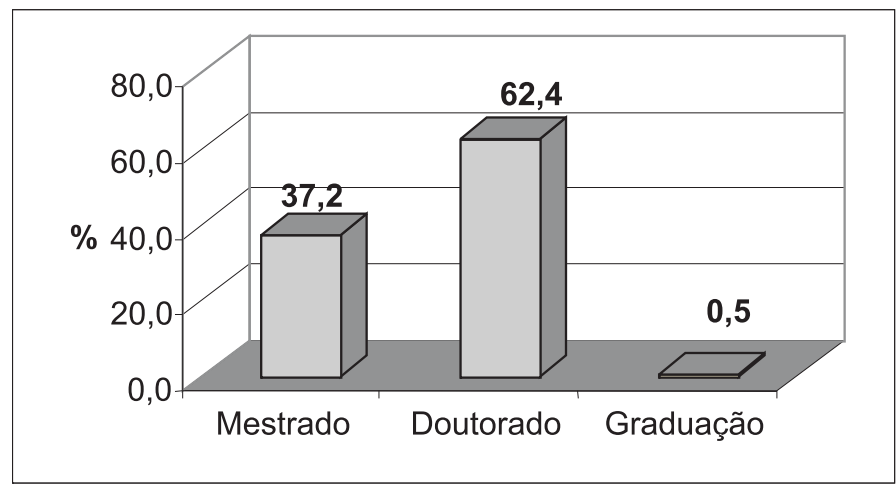

Fonte: banco de dados da ANPAD. 
A partir da seção que se segue serão discutidos não mais os processos e características internas e a montante do encontro (como suas características de submissão), mas aqueles que acontecem a jusante do mesmo.

\section{Resultados do Processo Seletivo}

Um dos aspectos mais importantes deste último encontro para a ANPAD, como associação que representa os interesses da totalidade de seus associados, foi a melhor distribuição de trabalhos por programa. Em 2001, as oito instituições de ensino com maior participação no evento, em termos de autorias e de coautorias, foram responsáveis por aproximadamente $70 \%$ dos trabalhos aceitos. Em 2002, foi necessário somar a participação das quatorze instituições com maior número de trabalhos aceitos (UFRGS, EAESP/FGV, USP, UFRJ, UFMG, UFBA, UFPE, UNISINOS, EBAPE/FGV, UnB, PUC-RJ, IBMEC, UFPR e UFSC) para se atingir o mesmo percentual. Esta mudança está longe de ser sutil. Na verdade, ela revela uma grande dinâmica de surgimento de novos programas com capacidade de produção científica de bom nível e de crescimento destes programas. É importante salientar, no entanto, que o número de trabalhos de uma dada instituição que são aceitos no encontro não é, isoladamente, um indicador de qualidade. Para que se derive dessa informação qualquer conclusão qualitativa, seria necessário transformar esses dados em informações mais pertinentes; por exemplo, dividindo os números de cada programa pela quantidade de seus docentes de pós-graduação. No entanto não é essa a finalidade deste texto que, como dito anteriormente, visa à apenas informar aos membros da comunidade o funcionamento e os resultados do encontro de 2002.

\section{Principais Resultados em Termos de Aceitação de Trabalhos por Área Temática}

A Figura 7, a seguir, mostra o percentual de trabalhos de cada um dos programas que tiveram $5 \%$ ou mais do total de trabalhos aceitos, em cada uma das seis grandes áreas de concentração do encontro de 2002. 
Figura 7: Participação Percentual de cada um dos Programas que Tiveram 5\% ou mais dos Trabalhos Aceitos nas Seis Maiores Áreas do XXVI ENANPAD

\begin{tabular}{|c|c|}
\hline Figura 7a: Marketing & $\begin{array}{c}\text { Figura 7b: Gestão de Pessoas e } \\
\text { Relações de Trabalho }\end{array}$ \\
\hline Outros & UFMG \\
\hline $\begin{array}{l}\text { Figura 7c: Estratégia } \\
\text { nas Organizações }\end{array}$ & $\begin{array}{c}\text { Figura 7d: Comportamento } \\
\text { Organizacional }\end{array}$ \\
\hline Outros & Outros \\
\hline $\begin{array}{c}\text { Figura 7e: Contabilidade e } \\
\text { Controladoria Gerencial }\end{array}$ & $\begin{array}{c}\text { Figura 7f: Administração } \\
\text { da Informação }\end{array}$ \\
\hline 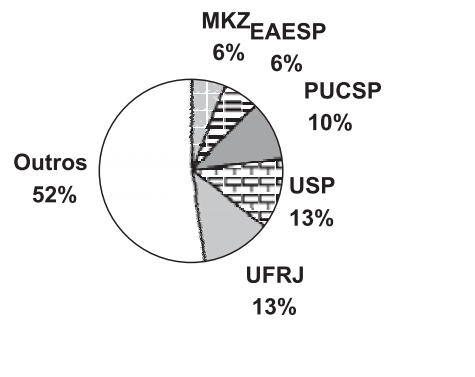 & Outros \\
\hline
\end{tabular}

Fonte: bancos de dados da ANPAD. 
Constata-se na Figura 7a que Marketing é uma das áreas de maior concentração da produção, uma vez que apenas três programas respondem por $54 \%$ de todos os trabalhos aceitos no encontro. Já as áreas de Estratégia nas Organizações e Comportamento Organizacional têm o resultado oposto, ou seja, grande dispersão em termos do percentual de trabalhos aceitos por programa. Nesse último caso, nenhum programa conseguiu isoladamente mais que $13 \%$ dos trabalhos aceitos, sendo necessário somar os percentuais dos sete programas com maior participação para alcançar o percentual acumulado dos três maiores na área de Marketing. A Figura 7e mostra outro fenômeno associado à concentração da produção. Desta feita, trata-se da concentração regional, já que quatro dos cinco programas que atingiram ou ultrapassaram os $5 \%$ do total de trabalhos aceitos na área de Contabilidade e Controladoria Gerencial são do Estado de São Paulo. Esse resultado certamente está ligado ao fato de que, por muitos anos, a USP tem sido a única instituição de ensino no país com um curso de doutorado na área.

Por fim, ressalta-se que várias instituições e programas sem grande tradição em termos do volume da produção científica nos encontros da ANPAD tiveram papel destacado em 2002, como, por exemplo: PUC-RG em Marketing; FEADMG em Gestão de Pessoas e Relações de Trabalho; Universidade de Coimbra em Estratégia nas Organizações; UFRN em Comportamento Organizacional; Universidade Mackenzie em Contabilidade e Controladoria Gerencial; e o IBMEC em Administração da Informação.

A Figura 8 mostra o resultado das três áreas com percentuais de submissão ente $7,4 \%$ e $6,8 \%$ do total de submissões. A Figura 8a mostra que a área de Finanças teve uma distribuição bastante homogênea em termos de trabalhos aceitos no encontro; observa-se, por outro lado, que são, aparentemente, poucos os programas produzindo na área.

A área formalmente denominada Organizações/Teoria das Organizações, revela uma distribuição sem grandes destaques (vide Figura 8b). Chama a atenção o aparecimento de outro newcomer, a UNIFOR.

Se as distribuições acima mencionadas não chegam a chamar a atenção, não se pode falar o mesmo da área de Gestão Pública e Governança, já que ela apresenta a maior concentração entre todas as áreas temáticas do XXVI ENANPAD. Nessa área temática, apenas dois programas responderam por 50\% de todos os trabalhos aceitos (vide Figura 8c). 
Figura 8: Participação Percentual de cada um dos Programas que Tiveram 5\% ou mais dos Trabalhos Aceitos em Finanças, Teoria das Organizações e Gestão Pública e Governança do XXVI ENANPAD

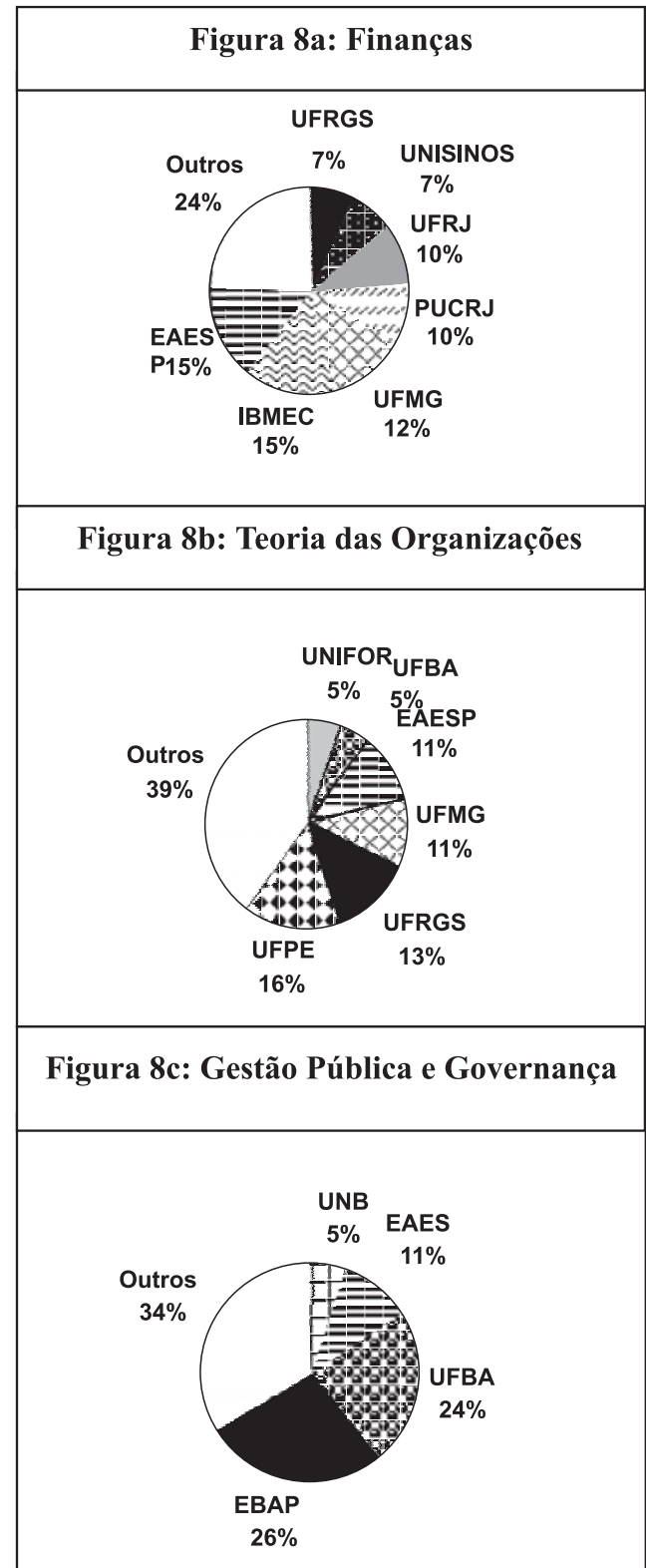

Fonte: bancos de dados da ANPAD. 
A mostra a mesma distribuição, ou seja, o percentual dos programas que tiveram ao menos 5\% do total de trabalhos aceitos para as seguintes áreas temáticas: Ensino e Pesquisa em Administração; Gestão de Ciência e Tecnologia; Políticas Públicas; Gestão de Operações e Logística; e Gestão Internacional.

Figura 9: Participação Percentual de cada um dos Programas que Tiveram 5\% ou mais dos Trabalhos Aceitos em Ensino e Pesquisa em Administração, Administração de Ciência e Tecnologia, Políticas Públicas e Gestão Internacional

\begin{tabular}{|c|c|}
\hline $\begin{array}{c}\text { Figura 9a: Ensino e Pesquisa em } \\
\text { Administração }\end{array}$ & $\begin{array}{c}\text { Figura 9b: Administração de Ciência } \\
\text { e Tecnologia }\end{array}$ \\
\hline PUCMG & Outros \\
\hline Figura 9c: Políticas Públicas & $\begin{array}{c}\text { Figura 9d: Gestão de Operações } \\
\text { e Logística }\end{array}$ \\
\hline UFMG & UFSCar \\
\hline \multicolumn{2}{|c|}{ Figura 9e: Gestão Internacional } \\
\hline UFRJ & 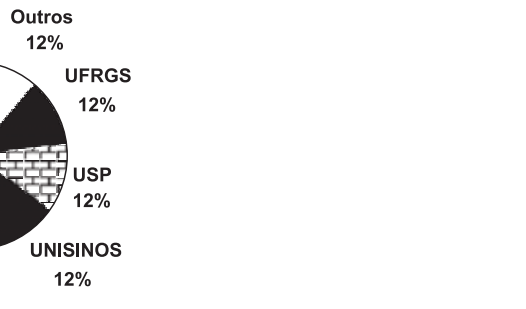 \\
\hline
\end{tabular}

Fonte: banco de dados da ANPAD. 
A Figura 9a (Ensino e Pesquisa em Administração) mostra dois newcomers com importante participação, a FECAP e a PUC-MG. Já a Figura 9b (Administração de Ciência e Tecnologia) exibe uma distribuição equilibrada, mas na qual apenas seis programas respondem por quase $80 \%$ dos trabalhos aceitos. Na área de Políticas Públicas (vide Figura 9c) a produção também é bem distribuída. Um dos destaques dessa área é a Fundação João Pinheiro, já que ela também não está entre os participantes tradicionais dos encontros da ANPAD. Também na área de Gestão de Operações e Logística (vide Figura 9d) há participações importantes de programas e instituições não tradicionais no evento. Esse é o caso da Universidade de São Carlos e, até certo ponto, da UNISINOS. Esta última, apesar de não tradicional, já se coloca entre os maiores programas, em termos do número total de trabalhos aceitos nos encontros recentes da ANPAD.

A Figura 9e retrata os resultados dos programas com maior número de trabalhos aceitos na área de Gestão Internacional. A distribuição é equilibrada entre poucos programas. O novo entrante em posição destacada, desta vez, é o IBMEC.

Por fim, deve-se mencionar que a área de Casos de Administração Brasileira teve apenas sete trabalhos aprovados: dois da PUC-SP; um da UFBA; um da UFRJ; um da EAESP/FGV; um da UNIFOR de Fortaleza; e um da PUC-RJ.

Em suma, pode-se dizer que a produção aceita para o encontro distribuiu-se de maneira saudável entre as mais variadas instituições e programas, tendo-se, paralelamente, a grata observação da emergência de vários novos e promissores associados da ANPAD. Esta renovação é um indicador da dinâmica do ensino e, principalmente, da pesquisa em Administração em nosso país, denotando claros sinais de renovação e de difusão geográfica dos conhecimentos na área.

\section{Considerações Finais}

Este texto teve como finalidade divulgar, junto à comunidade de pesquisadores da área de Administração, o funcionamento e os principais resultados do XXVI ENANPAD. As informações aqui coletadas mostram que o evento cresceu significativamente nos últimos anos, mas que, apesar desse crescimento, não se descuidou da qualidade, tanto no que tange à forma, quanto no que tange ao conteúdo dos trabalhos. Para que tal objetivo fosse alcançado, foi montado um sistema de trabalho bem estruturado e foram elaborados critérios de avaliação amplos e claros. 
A distribuição de trabalhos por áreas temáticas mostrou-se razoavelmente equilibrada e, aparentemente, compatível com tendências internacionais, justificando a manutenção de todas as áreas temáticas criadas em 2000.

O texto mostra, também, fortes sinais de que muitos dos novos entrantes do sistema já chegam com fôlego e competência científica capazes de produzir resultados impactantes, tanto em termos qualitativos, quanto em termos quantitativos.

Por fim, este texto visou a caracterizar o perfil dos autores e, por que não, do público dos encontros. Esta caracterização mostrou ser esse público majoritariamente composto por professores e, em segundo lugar, por estudantes de pósgraduação. Mais importante que essa constatação, foi o reconhecimento, caracterização e quantificação de um terceiro e grande grupo de autores: o dos professores-estudantes. Trata-se certamente de um fenômeno recente, baseado no enorme aumento de cursos, tanto de graduação quanto de pós-graduação em Administração. Este levantamento permite afirmar que já é quase uma utopia falar-se em estudantes de pós-graduação em regime de dedicação exclusiva, quer no nível do mestrado, quer no nível do doutorado. Que implicações esta constatação deve trazer para o desenho e o planejamento desses cursos? Será o estudante-professor (ou estudante de dedicação parcial) tão bem formado quanto o seu modelo anterior, o estudante de dedicação exclusiva?

A resposta a estas perguntas não é trivial. A Figura 10, a seguir, talvez nos forneça algumas pistas.

Figura 10: Desempenho dos Quatro Principais Grupos de Autores no Processo Seletivo do XXVI ENANPAD (Participações Percentuais no Universo de Trabalhos Submetidos e no Universo de Trabalhos Aceitos no Evento)

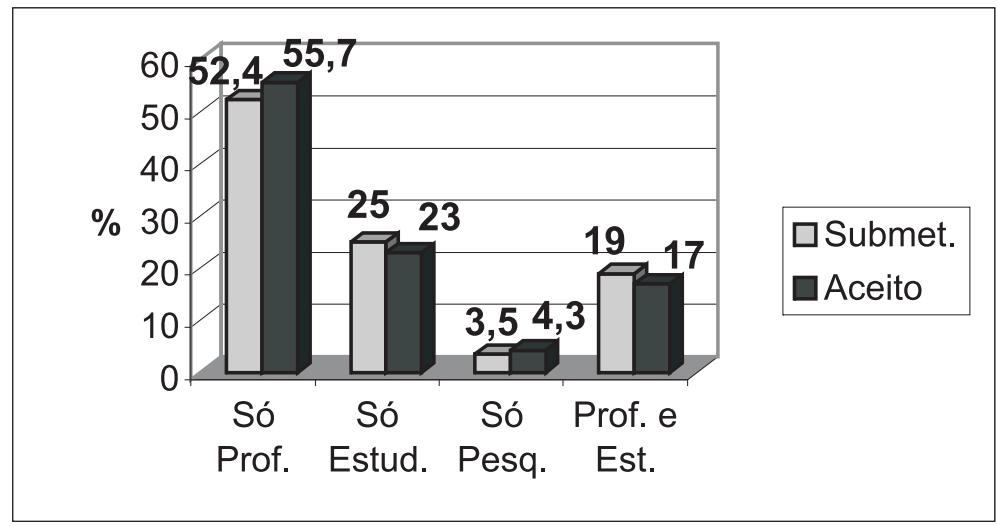

Fonte: banco de dados da ANPAD. 
A Figura mostra um desempenho não muito discrepante entre os grupos, porém claramente superior nos grupos dos Pesquisadores e Professores Plenos (com um ganho respectivo de 0,8 de 3,3 pontos percentuais), contra uma queda nos grupos de Estudantes Plenos e de Professores-Estudantes, ou vice-versa, de dois pontos percentuais (sobre bases respectivas de 25 e 19 pontos percentuais).

Trata-se, evidentemente, de assunto complexo, importante e instigante, que apenas começa a ser investigado. Os dados do evento permitem e sugerem uma análise mais detalhada desse desempenho dentro de cada grande grupo; mas isto deverá ser assunto para um estudo posterior.

\section{RefERÊnCIAS Bibliográficas}

BERTERO, C. O.;

CALDAS, M. P.;

WOOD JR., T.

Produção científica em administração de empresas: provocações, insinuações e contribuições para um debate local. In: ENCONTRO ANUAL DA ANPAD, 22., 1998, Foz do Iguaçu. Anais... Foz do Iguaçu: ANPAD, 1998. 1 CDROM.

CALDAS, M. P.;

TONNELLI, M. J.;

LACOMBE, B. M. B.

Espelho, espelho meu: meta-estudo da produção científica em recursos humanos nos ENANPAD da década de 90. In: ENCONTRO ANUAL DA ANPAD, 26., 2002, Salvador. Anais... Salvador: ANPAD, 2002. 1 CD-ROM.

HOPPEN, N. et al.

Sistemas de informação no Bra- sil: uma análise dos artigos científicos dos anos 90. In: ENCONTRO ANUAL DA ANPAD, 22., 1998, Foz do Iguaçu. Anais... Foz do Iguaçu: ANPAD, 1998. 1 CDROM.

MACHADO-DA-SILVA, C. L.; CUNHA, V. C.;

AMBONI, N.

Organizações: o estado da arte da produção acadêmica no Brasil. In: ENCONTRO ANUAL DA ANPAD, 14., 1990, Belo Horizonte. Anais... Belo Horizonte: ANPAD, 1990. v. 6. p. 11-28.

RODRIGUES FILHO, J.

Estudos críticos em administração no Brasil: classificação da produção do conhecimento sob a ótica da teoria crítica de Jurgen Habermas. João Pessoa, 2002. Tese (Concurso Professor Titular) - Universidade Federal da Paraíba. 
TEIXEIRA JR., F.

Análise dos métodos de pesquisa utilizados em artigos de administração da informação: levantamento dos artigos publicados nos ENANPADs de 1999 a 2002. In: ENCONTRO ANUAL DA ANPAD, 26., 2002, Salvador. Anais... Salvador: ANPAD, 2002. 1 CD-ROM.
VERGARA, S. C.;

CARVALHO JR., D. S.

Nacionalidade dos autores referenciados na literatura brasileira sobre organizações. In: ENCONTRO ANUAL DA ANPAD, 19., 1995, João Pessoa. Anais... João Pessoa: ANPAD, 1995. 1 CD-ROM. 